\title{
Identification of a Mo-Fe-S Cluster on NifEN by Mo K-Edge Extended X-ray Absorption Fine Structure
}

\author{
Simon J. George, ${ }^{\dagger}$ Robert Y. Igarashi, ${ }^{\ddagger}$ Cinthia Piamonteze, ${ }^{\dagger}$ Basem Soboh, ${ }^{\ddagger}$ \\ Stephen P. Cramer,,$+ \S$ and Luis M. Rubio ${ }^{*}, \neq$ \\ Department of Plant and Microbial Biology, University of California-Berkeley, 111 Koshland Hall, \\ Berkeley, California 94720, Advanced Biological and Environmental X-ray Facility, \\ Lawrence Berkeley National Laboratory, 1 Cyclotron Road, Berkeley, California 94720, and \\ Department of Applied Science, University of California-Davis, Davis, California 95616
}

Received August 31, 2006; E-mail: Irubio@nature.berkeley.edu

The iron-molybdenum cofactor (FeMo-co) is the complex metal-sulfur cofactor found within the active site of the molybdenum-iron protein (MoFe protein) component of the nitrogenase enzyme complex. ${ }^{1}$ FeMo-co is among the most complex metalsulfur cofactors known in biology and is composed of $7 \mathrm{Fe}, 9 \mathrm{~S}$, Mo, $\mathrm{X}(\mathrm{C}, \mathrm{N}$, or $\mathrm{O})$ and $R$-homocitrate. ${ }^{2}$ This cofactor is required for the nitrogenase $\mathrm{MoFe}$ protein to catalyze the reduction of $\mathrm{N}_{2}$ to $\mathrm{NH}_{3}$ in nitrogen-fixing organisms, such as Azotobacter vinelandii or Rhodospirillum rubrum, and thus is essential for the input of nitrogen into the biosphere.

Compared to simpler clusters, the large size and high complexity of FeMo-co is supported by a biosynthetic pathway that is more complex than that required for building simpler clusters such as $\left[\mathrm{Fe}_{2} \mathrm{~S}_{2}\right],\left[\mathrm{Fe}_{3} \mathrm{~S}_{4}\right]$, or $\left[\mathrm{Fe}_{4} \mathrm{~S}_{4}\right]$. A series of combined genetic and biochemical studies have shown that multiple proteins, mostly encoded by nitrogen fixation (nif) genes, are involved in the biosynthesis of FeMo-co. ${ }^{3}$ FeMo-co is assembled outside of the $\mathrm{MoFe}$ protein and then is inserted into the apo-MoFe protein to constitute an active nitrogenase capable of nitrogen reduction. A full description of the biosynthetic pathway and the relevant proteins is available in recent reviews. ${ }^{3}$

NifB, NifEN, and the nitrogenase $\mathrm{Fe}$ protein (NifH) are minimally essential for the biosynthesis of FeMo-co, and novel enzymatic reactions for assembling and modifying $\mathrm{Fe}-\mathrm{S}$ clusters are hypothesized for NifB and NifEN. NifB, a member of the "SAM-radical enzyme" family, ${ }^{4}$ has recently been isolated and used to start the assembly of FeMo-co in vitro using $\mathrm{Fe}^{2+}$ and $\mathrm{S}^{2-}$ as its initial substrates. ${ }^{5}$ NifB catalyzes the formation of NifB-co, an isolable low-molecular-weight intermediate of the FeMo-co biosynthesis pathway that is hypothesized to provide the majority of the Fe and $\mathrm{S}$ atoms of FeMo-co, but not Mo. ${ }^{6}$ In experiments using anoxic native electrophoretic analysis, the NifEN complex, which is homologous to the $\mathrm{MoFe}$ protein, ${ }^{7}$ has been shown to bind NifB-co. ${ }^{8}$ NifEN serves as a molecular scaffold where some of the steps for the assembly of FeMo-co occur. The NifEN protein is hypothesized to convert NifB-co to FeMo-co by the addition of (i) possibly more $\mathrm{Fe}$ and $\mathrm{S}$, (ii) $\mathrm{Mo}$, and (iii) $R$-homocitrate in a series of reactions, some of which are dependent on NifH. ${ }^{9,10}$ There is also experimental evidence to suggest that $\mathrm{NifH}$ may bind a FeMo-co precursor at some stage and that NifX may be involved in the attachment of $R$-homocitrate..$^{9} \mathrm{NafY}$ binds the completed FeMo-co with high affinity, and it is predicted to increase the efficiency of inserting it into the apo-MoFe protein. ${ }^{11}$

As mentioned above, the combined action of NifEN and NifH have been shown to be required for conversion of NifB-co into

\footnotetext{
¥University of California, Berkeley.

$\dagger$ Lawrence Berkeley National Laboratory

$\S$ University of California, Davis.
}

FeMo-co. The mechanism of this conversion that occurs within the NifEN protein is largely unknown. Among the key questions are (i) what are the structures of the $\mathrm{Fe}-\mathrm{S}$ and Mo substrates? (ii) how many and what types of metal clusters are present on NifEN? (iii) how do the substrates interact with the pre-existing clusters? The NifEN complex as purified from a $\triangle$ nifHDK strain of $A$. vinelandii (DJ1041) by an improved procedure contains 24 Fe per tetramer, ${ }^{12}$ but the distribution of these $\mathrm{Fe}$ atoms in the different clusters has not been well characterized. At minimum, NifEN has two $\left[\mathrm{Fe}_{4} \mathrm{~S}_{4}\right]$ clusters of unknown function and an $\mathrm{Fe}-\mathrm{S}$ cluster that serves as a FeMo-co precursor. ${ }^{13}$ In addition, the as-purified NifEN has also been determined to contain substoichiometric amounts of bound Mo. ${ }^{12}$ Biochemical studies have shown that the bound Mo is suitable for in vitro FeMo-co synthesis. In this study, the ligand environment of the Mo bound on the as purified NifEN is examined by Mo K-edge X-ray absorption spectroscopy (XAS).

The Mo K near-edge spectrum of NifEN is presented in Figure 1A. The quantity of Mo present, determined by integrating the Mo $\mathrm{K} \alpha$ fluorescence at $20.5 \mathrm{keV}$ incident energy, was $0.13 \mathrm{mM}$ for $0.9 \mathrm{mM}$ NifEN tetramer. The spectrum exhibits relatively little structure. When compared to the spectrum from A. vinelandii $\mathrm{MoFe}$ protein (Figure 1A,B), the two edges occur at similar energies, but the MoFe protein has additional edge structure around $20.020 \mathrm{keV}$ while NifEN has a shoulder at $20.008 \mathrm{keV}$. This indicates that the Mo sites in NifEN and the MoFe protein have similar oxidation states but significantly different ligand fields.

Analysis of the extended X-ray absorption fine structure (EXAFS) data (Figure 1C,D) shows that the spectrum fits well to $3 \mathrm{Fe}$ atoms at a distance of $2.68 \AA$ and $3 \mathrm{~S}$ atoms at $2.35 \AA$. These distances are very similar to those observed for the nitrogenase M-center (FeMo-co), ${ }^{14}$ and they strongly suggest that the Mo is part of a cluster whose first two coordination spheres resemble a $\left[\mathrm{MoFe}_{3} \mathrm{~S}_{4}\right]$ cubane fragment as part (or whole) of some cluster on NifEN. Attempts to include non-sulfur $\mathrm{Mo}-\mathrm{O}$ or $\mathrm{Mo}-\mathrm{N}$ interactions did not give appreciably better fits. While the presence of short Mo-O ligands below $2.0 \AA$, consistent with a $\mathrm{Mo}=\mathrm{O}$ double bond, could be excluded, it was not possible to ascertain the presence of longer $\mathrm{Mo}-\mathrm{O} / \mathrm{N}$ in the 2.0-2.3 $\AA$ range, as these correlate strongly with the $\mathrm{Mo}-\mathrm{S}$ interaction over the $k$-range of the data. ${ }^{15}$

The presence of Mo in a $\mathrm{Fe}-\mathrm{S}$ cluster environment raises the question of which cluster on NifEN contains the Mo. Possibilities for the Mo-containing cluster could involve (i) finished FeMo-co, (ii) a FeMo-co precursor containing Mo, or (iii) another separate cluster that may be permanent or transient. These three possibilities are discussed below.

First, the Mo bound to NifEN is unlikely to be part of finished FeMo-co, because the differences in the Mo K-edge spectrum of 

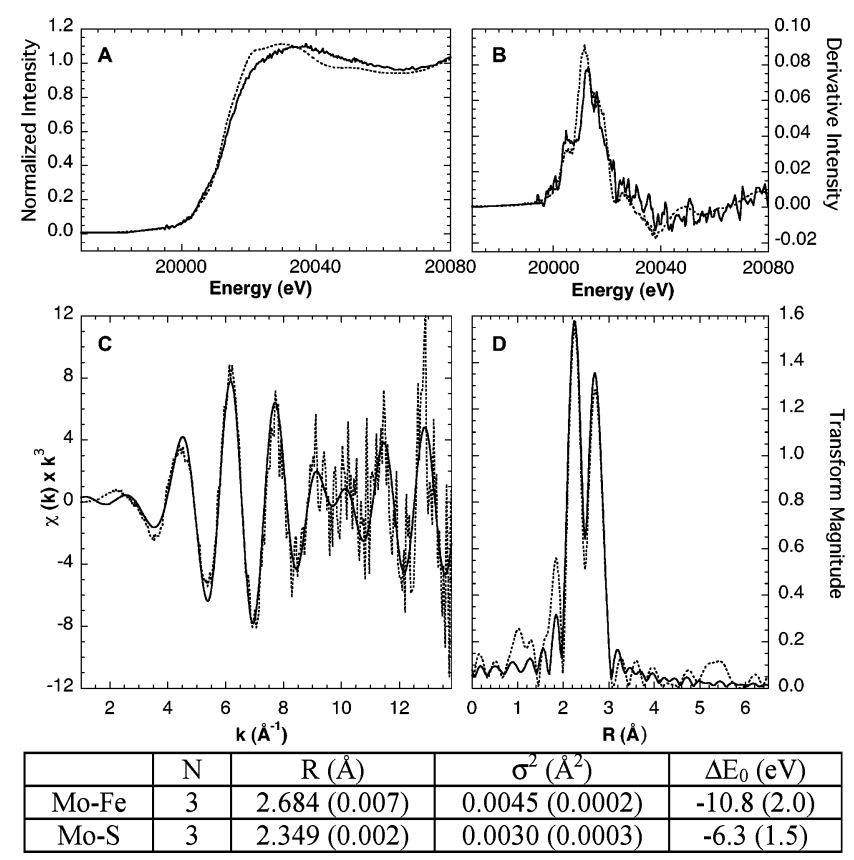

Figure 1. Mo K-edge XANES and EXAFS recorded from of $A$. vinelandii NifEN. (A) XANES spectrum of NifEN (solid line) compared with $A$. vinelandii MoFe protein (broken line). (B) First derivative spectra from A (C) $k^{3}$ weighted EXAFS spectrum of NifEN (broken line) and analysis (solid line). (D) Mo-Fe phase corrected Fourier transforms from C. (bottom panel) Fitting parameters, where $N$ is the number of atoms, $R$ the distance, $\sigma^{2}$ the Debye -Waller factor, and $\Delta E_{0}$ the offset from the threshold energy. The fitting uncertainties are in brackets. In the presented fit, $N$ has been constrained to a half-integer.

NifEN and the MoFe protein indicate that the ligand environment is not the same, possibly owing to a lack of homocitrate. Moreover, the NifEN protein was isolated from a strain lacking NifH, which is required for the final steps of FeMo-co biosynthesis.

Second, we consider it unlikely that the Mo is part of a NifB-co derivative bound on NifEN because of results from our laboratory on the transfer of a Fe-S cluster between NifEN and NifX. These experiments show that the NifX protein can extract an $\mathrm{Fe}-\mathrm{S}$ cluster, designated as the VK-cluster, from NifEN charged with a NifB-co derivative. ${ }^{16}$ The NifX-bound VK-cluster can be used as a FeMoco precursor in an in vitro FeMo-co synthesis reaction, indicating that the VK-cluster is the extracted form of the NifB-co derivative bound to NifEN. Metal quantification by inductively-coupled optical-emission spectroscopy showed that the VK-cluster contains virtually no Mo, ${ }^{16}$ which, in turn, suggests that the NifEN-bound NifB-co derivative does not contain Mo. ${ }^{17}$ We note that a better Mo EXAFS data set with longer $k$-range and lower noise levels should be able to demonstrate whether the Mo is part of finished FeMo-co or a NifB-co derivative through the presence or absence of the long-range $5 \AA \mathrm{Mo}-\mathrm{Fe}$ interaction observed in MoFe protein.

If the Mo within NifEN is not part of a large cluster, it may be part of a simpler metal-sulfur cluster. The EXAFS data supports the existence of a $\left[\mathrm{MoFe}_{3} \mathrm{~S}_{3+\mathrm{X}}\right]$ cluster. The presence of an additional $\left[\mathrm{MoFe}_{3} \mathrm{~S}_{3+\mathrm{X}}\right]$ cluster on NifEN, separate from the $\left[\mathrm{Fe}_{4} \mathrm{~S}_{4}\right]$ previously identified by resonance Raman measurements, ${ }^{13(a)}$ is not unreasonable to accommodate the reactions hypothesized to occur within NifEN to convert NifB-co into FeMo-co. An additional cluster would also be compatible with the number of $\mathrm{Fe}$ atoms determined for the as-purified NifEN complex. ${ }^{12} \mathrm{~A}\left[\mathrm{MoFe}_{3} \mathrm{~S}_{3+\mathrm{x}}\right]$ cluster on NifEN is consistent with the likely existence of a $\left[\mathrm{Fe}_{3} \mathrm{~S}_{4}\right]$ cluster on NifEN. Previous EPR inspection of NifEN oxidized by either indigo carmine or thionine revealed a broad asymmetric isotropic signal at $g=1.95 .{ }^{13} \mathrm{EPR}$ signals having similar line shape are characteristic of $S=1 / 2$ triferric $\left[\mathrm{Fe}_{3} \mathrm{~S}_{4}\right]^{1+}$ clusters in proteins, ${ }^{18}$ and the reduced $\left[\mathrm{Fe}_{3} \mathrm{~S}_{4}\right]^{0}$ state is known to be able to coordinate heterometals to complete a $\left[\mathrm{MFe}_{3} \mathrm{~S}_{4}\right]$ cubane. ${ }^{19}$ Hence, a $\left[\mathrm{Fe}_{3} \mathrm{~S}_{4}\right]$ center may serve as the initial Mo binding site either by reductive coupling to molybdate or from a reduced Mo species. The resulting $\left[\mathrm{MoFe}_{3} \mathrm{~S}_{4}\right]$ within NifEN may well act as Mo donor for the bound NifB-co derived FeMo-co precursor in the protein complex. This hypothesis is currently being examined in our laboratory.

Acknowledgment. We thank Paul W. Ludden for discussions and support. This work was supported by NIGMS, NIH Grant GM35332 to Paul Ludden, and Grants EB-001962 and GM-65440 to S.P.C. The Advanced Biological and Environmental X-ray Facility is supported by the U.S. DOE OBER. Portions of this research were carried out at the Stanford Synchrotron Radiation Laboratory (SSRL), a national user facility operated by Stanford University on behalf of the DOE, OBES. The SSRL Structural Molecular Biology Program is supported by the DOE, OBER, and the NIH, National Center for Research Resources, Biomedical Technology Program.

Supporting Information Available: Experimental procedures and additional EXAFS fits. This material is available free of charge via the Internet at http://pubs.acs.org.

\section{References}

(1) (a) Ludden, P. W.; Rangaraj, P.; Rubio, L. M. In Catalysts for Nitrogen Fixation: Nitrogenases, Relevant Chemical Models, and Commercial Processes; Smith, B. E., Richards, R. L., Newton, W. E., Eds.; Kluwer: Dordretch, The Netherlands, 2004; pp 219-253. (b) Shah, V. K.; Brill, W. J. Proc. Natl. Acad. Sci. U.S.A. 1977, 74, 3249-3253.

(2) (a) Einsle, O.; Tezcan, F. A.; Andrade, S. L.; Schmid, B.; Yoshida, M.; Howard, J. B.; Rees, D. C. Science 2002, 297, 1696-1700. (b) Hoover, T. R.; Robertson, A. D.; Cerny, R. L.; Hayes, R. N.; Imperial, J.; Shah, V. K.; Ludden, P. W. Nature 1987, 329, 855-857. (c) Chan, M. K.; Kim J.; Rees, D. C. Science 1993, 260, 792-794.

(3) (a) Dos Santos, P. C.; Dean, D. R.; Hu, Y.; Ribbe, M. W. Chem. Rev 2004, 104, 1159-1174. (b) Rubio, L. M.; Ludden, P. W. J. Bacteriol. 2005, 187, 405-414.

(4) Sofia, H. J.; Chen, G.; Hetzler, B. G.; Reyes-Spindola, J. F.; Miller, N. E. Nucleic Acids Res. 2001, 29, 1097-106.

(5) Curatti, L.; Ludden, P. W.; Rubio, L. M. Proc. Natl. Acad. Sci. U.S.A. 2006, 103, 5297-5301.

(6) Shah, V. K.; Allen, J. R.; Spangler, N. J.; Ludden, P. W. J. Biol. Chem. 1994, 269, 1154-1158.

(7) Brigle, K. E.; Weiss, M. C.; Newton, W. E.; Dean, D. R. J. Bacteriol 1987, 169, 1547-1553.

(8) Roll, J. T.; Shah, V. K.; Dean, D. R.; Roberts, G. P. J. Biol. Chem. 1995 $270,4432-4437$.

(9) Rangaraj, P.; Ludden, P. W. J. Biol. Chem. 2002, 277, 40106-40111.

(10) (a) Hu, Y.; Corbett, M. C.; Fay, A. W.; Webber, J. A.; Hodgson, K. O. Hedman, B.; Ribbe, M. W. Proc. Natl. Acad. Sci. U.S.A. 2006, 103 17125-17130. (b) Hu, Y.; Corbett, M. C.; Fay, A. W.; Webber, J. A.; Hodgson, K. O.; Hedman, B.; Ribbe, M. W. Proc. Natl. Acad. Sci. U.S.A 2006, 103, 17119-17124.

(11) Rubio, L. M.; Singer, S. W.; Ludden, P. W. J. Biol. Chem. 2004, 279 19739-19746.

(12) Soboh, B.; Igarashi, R. Y.; Hernandez, J. A.; Rubio, L. M. J. Biol. Chem 2006, 281, 36701-36709.

(13) (a) Goodwin, P. J.; Agar, J. N.; Roll, J. T.; Roberts, G. P.; Johnson, M. K.; Dean, D. R. Biochemistry 1998, 37, 10420-10428. (b) Goodwin, P. J. Ph.D. Dissertation, Virginia Polytechnic Institute, 1999. (c) Hu, Y.; Fay, A. W.; Ribbe, M. W. Proc. Natl. Acad. Sci. U.S.A. 2005, 102, 32363241.

(14) Christiansen, J.; Tittsworth, R. C.; Hales, B. J.; Cramer, S. P. J. Am. Chem. Soc. 1995, 117, 10017-10024

(15) (a) George, G. N. J. Biol. Inorg. Chem. 1997, 2, 790-796. (b) Marginally improved fits could be obtained with combinations of Mo-O interactions at $\sim 2.0 \AA$ and $\sim 2.3 \AA$, but these interactions correlate with each other and the Mo-S making unambiguous assignment impossible with the current data set (see Supporting Information).

(16) Hernandez, J. A.; Igarashi, R. Y.; Soboh, B.; Curatti, L.; Ludden, P. W.; Dean, D. R.; Rubio, L. M. Mol. Microbiol. 2007, 63, 177-192.

(17) We note that the nonstoichiometric quantitation of Mo in our NifEN samples allows the possibility that Mo bound to the NifB-co derivative is simply not extracted by NifX. However, as NifX readily binds FeMo-co as well as NifB-co, this possibility seems unlikely.

(18) Beinert, H.; Thomson, A. J. Arch. Biochem. Biophys. 1983, 222, 333-361.

(19) For example, see: Butt, J. N.; Armstrong, F. A.; Breton, J.; George, S J.; Thomson, A. J.; Hatchikian, E. C. J. Am. Chem. Soc. 1991, 113 6663-6670.

JA0663428 